\title{
The Source of Enhanced Cognitive Control in Bilinguals: Evidence From Bimodal Bilinguals
}

\section{Citation}

Emmorey, Karen, Gigi Luk, Jennie E. Pyers, and Ellen Bialystok. 2008. “The Source of Enhanced Cognitive Control in Bilinguals: Evidence From Bimodal Bilinguals." Psychological Science 19 (12) (December): 1201-1206. doi:10.1111/j.1467-9280.2008.02224.x. http://dx.doi.org/10.1111/ j.1467-9280.2008.02224.x.

\section{Published Version}

doi:10.1111/j.1467-9280.2008.02224.x

\section{Permanent link}

http://nrs.harvard.edu/urn-3:HUL.InstRepos:12122308

\section{Terms of Use}

This article was downloaded from Harvard University's DASH repository, and is made available under the terms and conditions applicable to Other Posted Material, as set forth at http:// nrs.harvard.edu/urn-3:HUL.InstRepos:dash.current.terms-of-use\#LAA

\section{Share Your Story}

The Harvard community has made this article openly available.

Please share how this access benefits you. Submit a story.

\section{Accessibility}




\title{
The Source of Enhanced Cognitive Control in Bilinguals:
}

\section{Evidence From Bimodal Bilinguals}

\author{
Karen Emmorey ${ }^{1}$, Gigi Luk ${ }^{2}$, Jennie E. Pyers ${ }^{3}$, and Ellen Bialystok ${ }^{2}$ \\ ${ }^{1}$ San Diego State University \\ ${ }^{2}$ York University \\ ${ }^{3}$ Wellesley College
}

\begin{abstract}
Bilinguals often outperform monolinguals on nonverbal tasks that require resolving conflict from competing alternatives. The regular need to select a target language is argued to enhance executive control. We investigated whether this enhancement stems from a general effect of bilingualism (the representation of two languages) or from a modality constraint that forces language selection. Bimodal bilinguals can, but do not always, sign and speak at the same time. Their two languages involve distinct motor and perceptual systems, leading to weaker demands on language control. We compared the performance of 15 monolinguals, 15 bimodal bilinguals, and 15 unimodal bilinguals on a set of flanker tasks. There were no group differences in accuracy, but unimodal bilinguals were faster than the other groups; bimodal bilinguals did not differ from monolinguals. These results trace the bilingual advantage in cognitive control to the unimodal bilingual's experience controlling two languages in the same modality.
\end{abstract}

A growing number of studies have reported advantages in nonverbal executive control tasks for bilingual children (Bialystok, 2001; Carlson \& Meltzoff, 2008; Mezzacappa, 2004) and adults (Bialystok, Craik, Klein, \& Viswanathan, 2004; Bialystok, Craik, \& Ryan, 2006; Costa, Hernandez, \& Sebastián-Gallés, 2008). One explanation for this enhancement is that the regular use of two languages requires a mechanism to control attention and select the target language - an experience that may enhance a general control mechanism. Evidence from neuroimaging and patient studies suggests that the same neural regions (e.g., dorsolateral prefrontal and anterior cingulate cortices) are engaged during both languageswitching tasks and nonverbal control tasks, supporting the interpretation that the mechanism for language control and selection is domain general (Fabbro, Skrap, \& Aglioti, 2000; Fan, Flombaum, McCandliss, Thomas, \& Posner, 2003; Hernandez, Dapretto, Mazziotta, \& Bookheimer, 2001; Rodriguez-Fornells et al., 2005).

We investigate whether the bilingual advantage in executive control stems from the conflict that arises from the need to select only one language for production or from the bilingual's representation of two language systems. Bilinguals who know two spoken languages (unimodal bilinguals) cannot produce two words at the same time; that is, they cannot simultaneously say dog and perro. In contrast, bimodal bilinguals who know both a spoken and a signed language can produce lexical items from both languages at the same time (Emmorey, Borinstein, Thompson, \& Gollan, 2008). Even while speaking English with nonsigners, bimodal bilinguals sometimes produce elements of American Sign Language

Copyright (C 2008 Association for Psychological Science

Address correspondence to Karen Emmorey, Laboratory for Language and Cognitive Neuroscience, San Diego State University, 6495 Alvarado Rd., Suite 200, San Diego, CA 92120, e-mail: kemmorey@ mail.sdsu.edu. 
(ASL; Casey \& Emmorey, in press; Pyers \& Emmorey, 2008). Like unimodal bilinguals, bimodal bilinguals have two available languages, but they are not necessarily constrained to select only one language for production, even in monolingual interactions. Here, we examine whether the bilingual advantage in executive control stems from a modalityspecific articulatory constraint that forces language selection. If so, bimodal bilinguals should not show the same advantage that has been observed for unimodal bilinguals.

In contrast to this view, the bilingual advantage could follow from a modality-independent effect of having two language representational systems. Bilinguals are well-practiced and experienced with coding a single lexical concept in two languages. Consistent with this experience, bilingual children show enhancements on dimensional card-sorting tasks that require the same concept to be re-coded in a different way (Bialystok, 1999; Bialystok \& Martin, 2004) and on ambiguous figures tasks that require children to reinterpret a reversible image (Bialystok \& Shapero, 2005). Like unimodal bilinguals, bimodal bilinguals must code the same lexical concept in two different languages. Therefore, if the bilingual advantage stems from knowledge of two language systems, then bimodal bilinguals should perform as well as unimodal bilinguals, and both groups should outperform monolinguals on executive control tasks.

\section{METHOD}

\section{Participants}

Forty-five adults ( 28 females, 17 males; mean age $=47.76$ years, $S D=6.18$ years) were equally distributed across three groups: English monolinguals, bimodal bilinguals, and unimodal bilinguals. Table 1 provides the following participant characteristics: age, years of formal education, proficiency ratings, and age of English acquisition. The groups did not differ in age, $F(2,42)=1.69, p=.20, p_{\text {rep }}=.73$; socioeconomic status as measured by education level, $F(2,42)=2.26, p=.12, p_{\text {rep }}=.80$; or area of residence-all participants lived in middle-class neighborhoods.

All bilinguals reported using both languages daily. The bimodal bilinguals were hearing individuals born to deaf parents who acquired both English and ASL in their first year of life $(M=0.93$ years, $S D=1.36)$. The unimodal bilinguals were exposed to their non-English language from birth and acquired English during childhood ( $M=6.07$ years, $S D=0.59$ ). The non-English languages of the unimodal bilinguals included Cantonese, Italian, and Vietnamese. Although the two bilingual groups differed in their age of acquiring English, $t(19.1)=13.39,{ }^{1} p<.0001, p_{\text {rep }}=.99$, both bilingual groups had over 30 years' experience using both languages (see Table 1). The bimodal bilinguals' self-ratings for both English and $\mathrm{ASL}^{2}$ were the same for comprehension, $t(12)<1, p=.72, p_{\text {rep }}=.34$, and production, $t(13)<-1.1, p=.31, p_{\text {rep }}=.63$. However, the unimodal bilinguals rated their proficiency in the non-English language higher than in English for both comprehension, $t(14)=7.12, p<$. $0001, p_{\text {rep }}=.99$, and production, $t(14)=5.1, p=.0002, p_{\text {rep }}=.99$. The unimodal bilinguals' somewhat low self-ratings for English proficiency may reflect their strong heritage ties to their native culture (e.g., only speaking this language at home), and thus their ratings may indicate their level of comfort in English, rather than their communication skill.

To control for possible differences in nonverbal reasoning, participants were given four pattern-completion subtests from the Cattell Culture Fair Test (Cattell, 1967). Age-adjusted raw scores were converted to standardized scores. The participant groups did not differ significantly from each other on this measure, $F(2,42)<1, p=.51, p_{\text {rep }}=.49$ (see Table 1 ).

\footnotetext{
${ }_{1}^{1}$ Satterthwaite adjustment of degree of freedom is reported to account for heterogeneity of variance

${ }^{2}$ Two bimodal bilinguals did not rate their production and comprehension skills in ASL.
} 


\section{Procedure}

Participants were given a set of flanker tasks modified after Bunge, Dudukovic, Thomason, Vaidya, and Gabrieli (2002). The stimuli were red chevron heads flanked by four distractors, as shown in Figure 1. Participants were instructed to indicate the direction the red chevron was pointing as quickly and accurately as possible. There were three types of blocked trials. Control blocks consisted of trials in which a single red chevron was pointing either left or right. These blocks provided baseline response times. Go/no-go blocks were equally divided between go trials (indicate the chevron direction) and no-go trials (withhold response). For the go trials, a central red chevron was flanked by four red diamonds, two on each side, and for the no-go trials, the chevron was flanked by four red $X$ s. In this condition, participants must monitor and inhibit responses to the no-go trials while responding as rapidly as possible to the go trials. Conflict blocks consisted of an equal number of congruent trials (distractors pointed in the same direction as the target red chevron) and incongruent trials (distractors pointed in the opposite direction). Unlike the trials in the go/no-go block, the red chevron could be in the center or one place to the left or right of the middle position. In the conflict condition, participants must focus attention only on the direction of the target chevron while ignoring the flanking distractors, which switch between congruent and incongruent.

The control and flanker tasks were administered using a laptop computer with a mouse on each side. Participants were instructed to put one hand on each mouse and to respond by pressing the button on the left mouse when the chevron pointed to the left and the button on the rightmouse when the chevron pointed to the right. Each trial began with a $250 \mathrm{~ms}$ fixation cross in the middle of the screen, followed by the stimulus presentation for 2,000 ms or until a response was made. Each of the three block types was presented twice. Control blocks were presented as the first and last blocks, with go/no-go and conflict blocks alternating between them. The order of go/no-go and conflict blocks was counterbalanced across participants. In total, there were 96 control trials, 96 go/no-go trials, and 96 conflict trials. Each block began with a practice set of 12 trials with feedback. Presentation of trials was randomized within each block, and direction of target response was counterbalanced. Both response time and accuracy were measured, and response time for trials with incorrect responses were excluded.

\section{RESULTS}

Accuracy on the flanker task was high for all groups and all conditions, ranging from $97 \%$ to $100 \%$, with no significant differences across groups, $F(2,42)<2.37, p>.11, p_{\text {rep }}>.40$. The mean reaction times in each condition by group are presented in Figure 2. A Group (3) $\times$ Task (4) mixed analysis of variance was conducted to analyze the response time data. There was a significant group main effect, $F(2,42)=4.73, p=.01, p_{\text {rep }}=.94, \eta_{p}{ }^{2}=.18$, and a significant task main effect, $F(3,126)=132.04, p<.0001, p_{\text {rep }}=.99, \eta_{p}{ }^{2}=.76$. In addition, a group-by-task interaction was observed, $F(6,126)=4.21, p=.0007, p_{\text {rep }}=.99, \eta_{p}{ }^{2}=.17$. The significant interaction was further analyzed in a series of one-way analyses of variance comparing the groups' response times for each block.

There was no group difference in response time for the control condition, $F(2,42) 52.11, p$ $=.13, p_{\text {rep }}=.78$. There was a group difference for the go trials in the go/no-go condition, $F(2,42)=8.18, p=.001, p_{\text {rep }}=.98, \eta_{p}{ }^{2}=.28$, with unimodal bilinguals responding faster than the other groups, who did not differ from each other. Similarly, a group difference in the conflict block was found, $F(2,42)=3.82, p=.03$, $p_{\text {rep }}=.90, \eta_{p}{ }^{2}=.15$, with unimodal bilinguals responding faster in both congruent and incongruent trials than the other two groups, who again did not differ from each other. Within the conflict block, congruent trials 
were faster than incongruent trials, $F(1,42)=114.81, p<.0001, p_{\text {rep }}=.99, \eta_{p}{ }^{2}=.73$, with no interaction between group and congruency, $F(2,42)=0.14, p=.87$, $p_{\text {rep }}=.21$.

\section{DISCUSSION}

Replicating previous findings, unimodal bilinguals responded faster than monolinguals on executive control tasks (Bialystok et al., 2004; Costa et al., 2008; Yang, Shih, \& Lust, 2005). The superior performance of the unimodal bilinguals on the go trials in the go/no-go task suggests that they were better at monitoring the mixed block of trials and preparing for the "go" response, while also inhibiting a response for the intermixed no-go trials. All groups were equally accurate in inhibiting the response in the no-go trials, so there is no evidence for a language-group effect on that component of executive control. As in previous studies, unimodal bilinguals were faster than monolinguals on both the congruent and the incongruent trials for the conflict task (Bialystok et al., 2004; Bialystok, Craik, \& Luk, 2008; Costa et al., 2008; Martin-Rhee \& Bialystok, 2008). This pattern suggests that the bilingual advantage is not simply in increased inhibitory control but may also be found in other aspects of executive control, such as attentional mechanisms, monitoring processes, and task switching.

Crucially, however, the performance of bimodal bilinguals did not differ from monolinguals. Thus, the bilingual advantage for executive control does not arise simply from being bilingual. Like unimodal bilinguals, bimodal bilinguals have acquired two distinct syntactic systems, two lexicons, and even two phonological systems. ${ }^{3}$ Also, like unimodal bilinguals, they must select and control two languages-indeed, they do not simultaneously sign and speak all the time (Emmorey et al., 2008). Bimodal bilinguals need to suppress the production of ASL when speaking to English monolinguals, and they also must suppress the production of English when signing to deaf interlocutors.

However, the degree of control required for bimodal bilinguals is less than that for unimodal bilinguals. Specifically, in interactions with other bilinguals, unimodal bilinguals must codeswitch from one language to the other (e.g., Poplack, 1980). Bimodal bilinguals, on the other hand, rarely switch between languages, preferring to code-blend, that is, simultaneously produce signs and words (Emmorey et al., 2008). The bimodal bilingual participants in this study self-reported frequent code-blending with other ASL-English bilinguals $(M=4.92, S D$ $=2.19$, on a 7-point Likert scale: $1=$ never, $7=$ often; data available for 12 participants). Furthermore, in monolingual contexts, unimodal bilinguals must strongly suppress their other language because the production of an unknown foreign word would be met with surprise and confusion by their interlocutor. In contrast, bimodal bilinguals can and do produce ASL signs (probably unintentionally) when speaking to nonsigners (Casey \& Emmorey, in press). Such productions are not necessarily disruptive because co-speech gestures are ubiquitous, and listeners are not surprised by manual productions that accompany speech. Thus, the unimodal bilingual's life-long experience of constantly controlling the production of two languages in the same modality may lead to a more general enhancement of cognitive control.

Furthermore, unimodal and bimodal bilinguals face different perceptual requirements for attending to and comprehending their two languages. The input to children with deaf parents is frequently bimodal; parents often sign and speak at the same time (Baker \& van den Bogaerde, 2008; Petitto et al., 2001). Simultaneous input for unimodal bilinguals is impossible. The enhanced executive control observed for unimodal bilinguals might also

\footnotetext{
${ }^{3}$ Signed languages have a sublexical, nonmeaningful phonological structure (see Brentari, 1998, and Sandler \& Lillo-Martin, 2006, for phonological analyses of signed languages).
} 
stem from the need to attend to and perceptually discriminate between two spoken languages. In a recent study of bilingual infants, Conboy, Sommerville, and Kuhl (2008) found an association between cognitive control abilities and the ability to ignore acoustic cues irrelevant to phonemic categories. Whether the bilingual advantage in executive control is linked to language control during perception, production, or both awaits further research.

The results from the bimodal bilinguals in this study indicate that the source of the bilingual advantage arises from acquiring two languages in the same modality. We predict that bilinguals who are fluent only in two signed languages would also show an advantage in cognitive control compared to monolinguals. The fact that bimodal bilinguals do not show enhanced executive functions has implications for understanding the bilingual advantage in theory-of-mind development (Goetz, 2003). One explanation of the early acquisition of theory of mind by unimodal bilingual children is their advanced executive control abilities (Bialystok, 2001; Bialystok \& Senman, 2004). Our results would predict that bimodal bilingual children should not differ from monolingual children on these tasks. However, if the bilingual advantage is tied to perspective-taking (e.g., knowing who speaks which language), then bimodal and unimodal bilingual children should pattern together. With respect to the neural systems underlying executive function and nonverbal conflict control, our results would also predict that bimodal bilinguals and monolinguals would be similar.

Finally, the results point to critical roles for the allocation of attentional resources within modality and for the mitigating effects of between-modality distinctions in executive control and conflict resolution. The cross-modal nature of sign and speech makes attentional selection processes more efficient for bimodal bilinguals than for unimodal bilinguals. Unimodal bilinguals are constantly faced with more challenging production demands because their languages utilize the same articulation system. There are no cross-modal distinctions to ease selection. Indeed, conflict resolution and dual tasks are generally more difficult within a modality than across modalities (Alias, Morrone, \& Burr, 2006; Arnell \& Duncan, 2002). Thus, extensive practice with more difficult selection and control processes may improve response selection and attentional control in a way that generalizes from language to cognition for unimodal bilinguals. Bimodal bilinguals do not face the same processing demands, and thus do not show the same enhanced performance on executive control tasks despite showing enhanced performance on other nonlinguistic cognitive tasks that relate to sign language processing, such as spatial working memory, mental imagery, and face processing (see Emmorey, 2002, for a review). Further research may determine whether bimodal bilinguals exhibit an advantage for aspects of executive control not tapped by flanker tasks (e.g., monitoring attention cross-modally).

\section{Acknowledgments}

This research was supported by National Institutes of Health Grant R01 HD047736 (to K.E. and San Diego State University), a postdoctoral fellowship funded by National Institute on Deafness and Other Communication Disorders Training Grant 5 T32 DC00041 at University of California, San Diego (UCSD; to J.E.P.), and Canadian Institutes of Health Research Grant MOP57842 and National Sciences and Engineering Research Council Grant A2559 (to E.B.). We thank Helsa Borinstein and Brenda Nicodemus for assistance in data collection, and members of the UCSD Language Production Journal Club for their feedback on earlier drafts of this manuscript. Finally, we are grateful to all of the participants who made this research possible.

\section{REFERENCES}

Alias D, Morrone C, Burr D. Separate attentional resources for vision and audition. Proceedings of the Royal Society B. 2006; 273:1339-1345. [PubMed: 16777721]

Arnell KM, Duncan J. Separate and shared resources of dual task cost in stimulus identification and response selection. Cognitive Psychology. 2002; 44:105-147. [PubMed: 11863322] 
Baker, A.; van den Bogaerde, B. Codemixing in signs and words in input to and output from children. In: Plaza-Pust, C.; Morales Lopéz, E., editors. Sign bilingualism: Language development, interaction, and maintenance in sign language contact situations. Amsterdam: Benjamins; 2008. p. $1-27$.

Bialystok E. Cognitive complexity and attentional control in the bilingual mind. Child Development. 1999; 70:636-644.

Bialystok, E. Bilingualism in development: Language, literacy, and cognition. New York: Cambridge University Press; 2001.

Bialystok E, Craik FIM, Klein R, Viswanathan M. Bilingualism, aging, and cognitive control: Evidence from the Simon task. Psychology and Aging. 2004; 19:290-303. [PubMed: 15222822]

Bialystok E, Craik FIM, Luk G. Cognitive control and lexical access in younger and older bilinguals. Journal of Experimental Psychology: Learning, Memory, and Cognition. 2008; 34:859-873.

Bialystok E, Craik FIM, Ryan J. Executive control in a modified anti-saccade task: Effects of aging and bilingualism. Journal of Experimental Psychology: Learning, Memory, and Cognition. 2006; 32:1341-1354.

Bialystok E, Martin MM. Attention and inhibition in bilingual children: Evidence from the dimensional change card sort task. Developmental Science. 2004; 7:325-339. [PubMed: 15595373]

Bialystok E, Senman L. Executive processes in appearance-reality tasks: The role of inhibition of attention and symbolic representation. Child Development. 2004; 75:562-579. [PubMed: 15056206]

Bialystok E, Shapero D. Ambiguous benefits: The effect of bilingualism on reversing ambiguous figures. Developmental Science. 2005; 8:595-604. [PubMed: 16246250]

Brentari, D. A prosodic model of sign language phonology. Cambridge, MA: MIT Press; 1998.

Bunge SA, Dudukovic NM, Thomason ME, Vaidya CJ, Gabrieli JDE. Immature frontal lobe contributions to cognitive control in children: Evidence from fMRI. Neuron. 2002; 33:301-311. [PubMed: 11804576]

Carlson SM, Meltzoff AM. Bilingual experience and executive functioning in young children. Developmental Science. 2008; 11:282-298. [PubMed: 18333982]

Casey S, Emmorey K. Co-speech gesture in bimodal bilinguals. Language and Cognitive Processes. (in press).

Conboy BT, Sommerville JA, Kuhl PK. Cognitive control factors in speech at 11 months. Developmental Psychology. 2008; 44:1505-1512. [PubMed: 18793082]

Costa A, Hernandez AE, Sebastián-Gallés N. Bilin-gualism aids conflict resolution: Evidence from the ANT task. Cognition. 2008; 106:59-86. [PubMed: 17275801]

Emmorey, K. Language, cognition, and the brain: Insights from sign language research. Mahwah, NJ: Erlbaum; 2002.

Emmorey K, Borinstein HB, Thompson R, Gollan TH. Bimodal bilingualism. Bilingualism: Language and Cognition. 2008; 11:43-61.

Fabbro F, Skrap M, Aglioti S. Pathological switching between languages after frontal lesions in a bilingual patient. Journal of Neurology, Neurosurgery, and Psychiatry. 2000; 68:650-652.

Fan J, Flombaum JI, McCandliss BD, Thomas KM, Posner MI. Cognitive and brain consequences of conflict. NeuroImage. 2003; 18:42-57. [PubMed: 12507442]

Goetz PJ. The effects of bilingualism on theory of mind. Bilingualism: Language and Cognition. 2003; $6: 1-15$.

Hernandez AE, Dapretto M, Mazziotta J, Bookheimer S. Language switching and language representation in Spanish-English bilinguals: An fMRI study. NeuroImage. 2001; 14:510-520. [PubMed: 11467923]

Martin-Rhee MM, Bialystok E. The development of two types of inhibitory control in monolingual and bilingual children. Bilingualism: Language and Cognition. 2008; 11:81-93.

Mezzacappa E. Alerting, orienting, and executive attention: Developmental properties and sociodemographic correlates in an epidemiological sample of young, urban children. Child Development. 2004; 75:1373-1386. [PubMed: 15369520] 
Petitto LA, Katerelos M, Levy BG, Gauna K, Tetreault K, Ferraro V. Bilingual signed and spoken language acquisition from birth: Implications for the mechanisms underlying early bilingual language acquisition. Journal of Child Language. 2001; 28:453-496. [PubMed: 11449947]

Poplack S. Sometimes I'll start a sentence in Spanish Y TERMINO EN ESPAÑOL: Toward a typology of code-switching. Linguistics. 1980; 18:581-618.

Pyers J, Emmorey K. The face of bimodal bilingualism: Grammatical markers in American Sign Language are produced when bilinguals speak to English monolinguals. Psychological Science. 2008; 19:531-535. [PubMed: 18578841]

Rodriguez-Fornells A, van der Lugt A, Rotte M, Britti B, Heinze H-J, Munte TF. Second language interferes with word production in fluent bilinguals: Brain potential and functional imaging evidence. Journal of Cognitive Neuroscience. 2005; 17:422-433. [PubMed: 15814002]

Sandler, W.; Lillo-Martin, D. Sign language and linguistic universals. Cambridge, England: Cambridge University Press; 2006.

Yang, S.; Shih, J.; Lust, B. Exploring cognitive advantages of childhood bilingualism through new tests of executive attention. Poster presented at the biennial meeting of the Society for Research in Child Development; Atlanta, GA: 2005 April. 


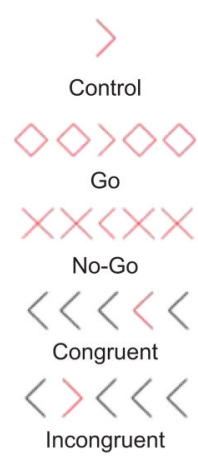

Fig. 1.

Sample stimuli used in the control and flanker tasks. On control trials, a single red chevron pointed either left or right. These trials provided baseline response times. Four kinds of flanker trials were presented. On go trials, a central red chevron was flanked by four red diamonds, two on each side. On no-go trials, the chevron was flanked by four red Xs. On congruent trials, distractor chevrons pointed in the same direction as the target red chevron. On incongruent trials, distractor chevrons pointed in the opposite direction as the target red chevron. 


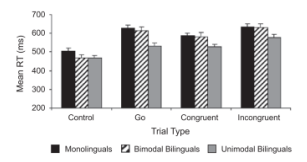

Fig. 2.

Mean response times (RTs) for monolinguals and unimodal and bimodal bilinguals for each trial type. Participants were asked to judge whether a target chevron pointed to the left or to the right. In control trials, a single red chevron was pointing either left or right. In go trials, the red chevron pointed either left or right and was flanked by four red diamonds (two on each side). In congruent trials, distractors pointed in the same direction as the target red chevron. In incongruent trials, distractors pointed in the opposite direction as the target red chevron. Error bars show $1 S D$. 
TABLE 1

Means and Standard Deviations for Participant Characteristics

\begin{tabular}{lccc}
\hline & & \multicolumn{2}{c}{ Bilinguals } \\
\cline { 3 - 4 } Group & Monolinguals & Bimodal & Unimodal \\
\hline Age (years) & $50.1(5.2)$ & $46.2(7.3)$ & $47.0(5.5)$ \\
Education (years) & $17.5(2.3)$ & $16.1(1.4)$ & $15.8(2.9)$ \\
Cattell standardized score & $113.9(3.5)$ & $111.2(13.4)$ & $117.5(17.8)$ \\
Self-ratings for English & & & \\
Understanding & - & $4.6(0.7)$ & $3.1(0.7)$ \\
Speaking & - & $4.5(0.7)$ & $3.1(0.9)$ \\
Self-ratings for non-English & & & \\
Understanding & - & $4.7(0.6)$ & $4.6(0.5)$ \\
Speaking & - & $4.3(1.0)$ & $4.4(0.6)$ \\
Age of acquisition for English & - & $0.9(1.4)$ & $6.1(0.6)$ \\
Years of speaking English & - & $45.3(7.3)$ & $40.9(5.5)$ \\
\hline
\end{tabular}

${ }^{a}$ Self-ratings are based on a 5 -point scale $(1=$ poor, $2=$ fair, $3=$ good, $4=$ very good, $5=$ excellent $)$. 